\section{Sturge-Weber syndrome associated with naevus of Ota}

\begin{abstract}
The association of Sturge-Weber syndrome with naevus of Ota is an infrequently reported phenomenon and there are only four previously described cases in the literature. In this paper we briefly review the literature regarding the coexistence of vascular and pigmentary naevi and present an additional patient with the association of the Sturge-Weber syndrome and naevus of Ota.
\end{abstract}

Key words Sturge-Weber syndrome, naevus of Ota

\section{Case report}

A 15-year-old girl was examined. Her parents were not blood relatives and there was no family history of neurocutaneous disease. The patient was the $3.8 \mathrm{~kg}$ product of a normal pregnancy and delivery. A port wine stain on the upper right portion of the face and the periorbital region was present at birth. The patient also presented a bluish discoloration of the right side of her face distributed over the lower eyelid, periocular region, temporal area and right ear (Fig. 1).

Magnetic resonance imaging revealed hyperplasia of the cavernous sinus due to vascular malformations in association with the facial angioma. On ophthalmological examination the patient's best corrected visual acuity was $20 / 25$ with $+1 \mathrm{sf}=+0.5$ cil $110^{\circ} \mathrm{OD}$ and 20/20 OS with no correction. The anterior segment was normal in the left eye. The findings in the anterior segment of the right eye consisted of vast areas of bluish pigmentation of the conjunctiva and episclera, heavily

S.M. Recupero

S. Abdoirahimzadeh

M. De Dominicis

R. Molio

Università di Roma 'La

Sapienza'

Il Clinica Oculistica

Policlinıco Umberto I

Viale del Policlinico

1-00161 Rome

Italy

Tel: $+39-6-490296$

Fax: $+39-6-4457706$
SANTI MARIA RECUPERO,

SOLMAZ ABDOLRAHIMZADEH, MARCO DE DOMINICIS, ROBERTO MOLLO slight nasal peripapillary hyperpigmentation and a choroidal angioma of approximately one papillary diameter in the extreme periphery of the temporal quadrant. The left fundus was normal. Visual fields of both eyes were normal.

\section{Discussion}

The coexistence of cutaneous haemangioma and pigmentary naevi was termed phakomatosis pigmentovascularis in 1947. ${ }^{1}$ These forms have been classified into four types and further divided into (a) localised (cutaneous) or (b) systemic on the basis of the presence or absence of systemic involvement ${ }^{2}$ (Table 1 ). The patient described in our report can be classified as type IIb. To our knowledge only four similar cases have been previously described in the literature. ${ }^{3--5}$ Some 20 other cases in the Japanese literature have been included in this group but not all patients presented melanosis bulbi or had the sole association of Sturge-Weber syndrome and naevus of Ota. Indeed, KlippelTrenaunay syndrome and naevus anaemicus were present in numerous cases.

Recent reports consider that the embryopathogenesis of the skin, leptomeningeal, and choroid and brain lesions of Sturge-Weber syndrome can be explained by a malformation of the primordial vascular plexus. ${ }^{6}$ In contrast, the hyperpigmentation of the skin, episclera and uvea in naevus of Ota is thought to be a result of maldevelopment and abnormality in the migration of neural crest cells, particularly melanocytes. ${ }^{7}$ In considering phakomatosis pigmentovascularis, there is evidence supporting developmental abnormalities of vasmotor nerve cells and melanocytes that originate in the embryonal neural crest. Kitamura et al. ${ }^{8}$ emphasised the electron microscopic differences between naevus flammeus in phakomatosis pigmentovascularis and port wine stain not accompanied by pigment abnormalities. Later, immunohistochemical studies showed the presence of perivascular nerves in port wine stains associated with phakomatosis pigmentovascularis, supporting this finding. ${ }^{9}$ Therefore, it has been postulated that the association of pigmentary and vascular naevi is caused by functional disorders of vasomotor 


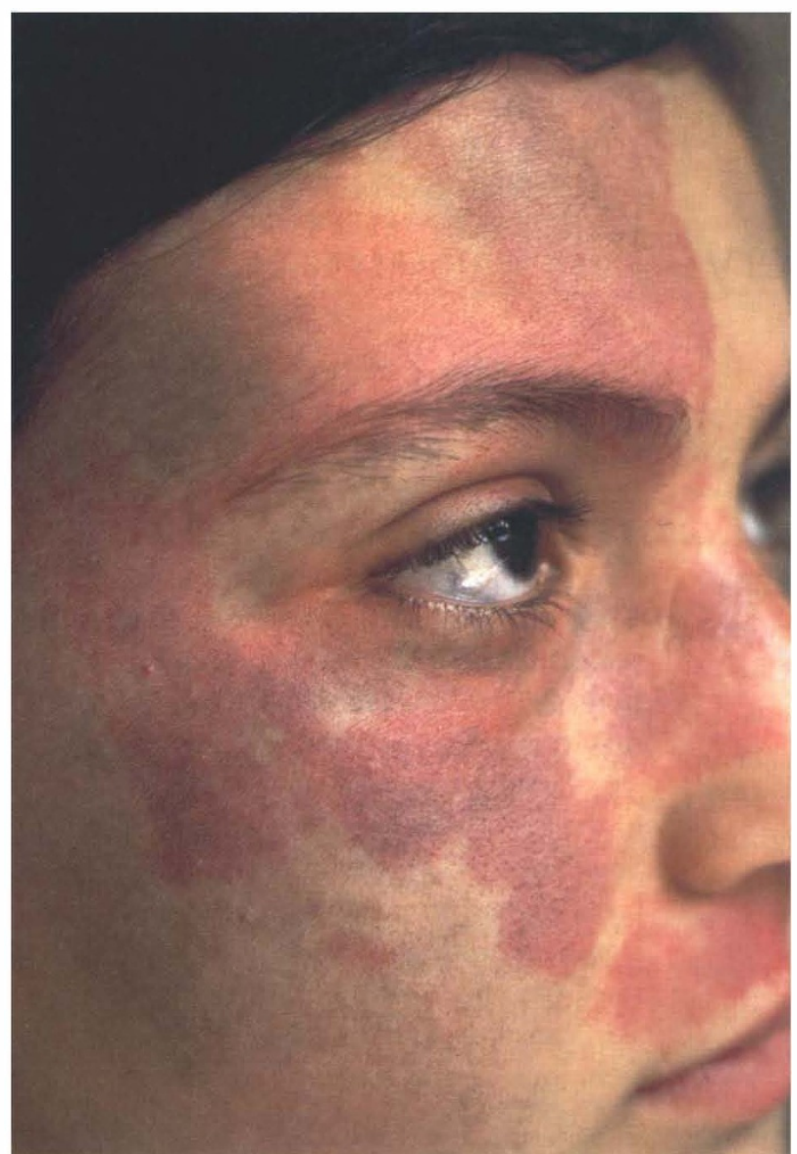

Fig. 1. Port-uine stain and bheish discoloration of the right side of the

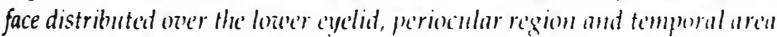

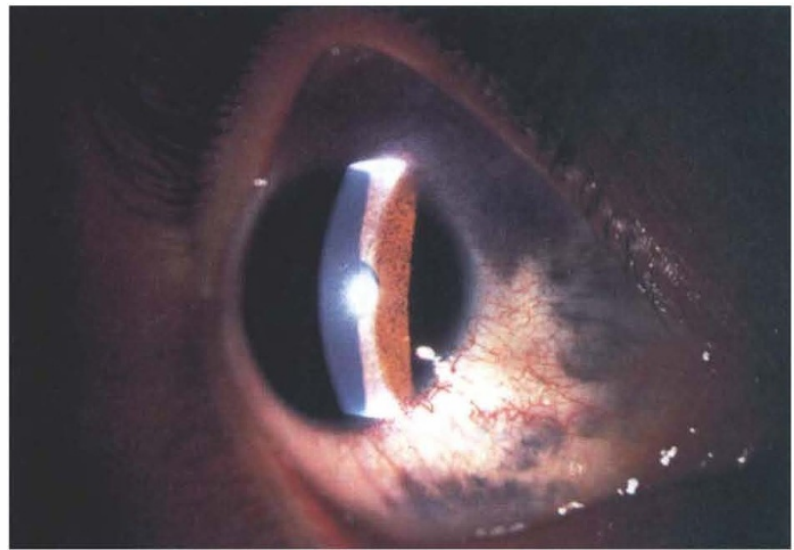

Fig. 2. Right eye. There are iast arens of hluish pigmentation of the conjunction and episclera. The heneily pigmented iris appears thickened with obscured crypts and riadial folds.

Table 1. Classificution of phatomatosis pigmentosenscularis

\begin{tabular}{ll}
\hline Type & Features \\
\hline $\mathrm{I} a, b^{\mathrm{d}}$ & Naevus flammeus and naevus pigmentosum et
\end{tabular}

II a, b Naevus flammeus, Mongolian spots,"+ nac'us anaemicus

III a,b Naevus flammeus, naevus spilus, I naevus anaemicus

IV a, b Naevus flammeus, Mongolian spots, naevus spilus, \pm naevus anaemicus

From Hasegaw'a and Yasuhara.

a, cutaneous disease only; b, cutaneous and sy'stemic disease.

'Mongolian spots (otherwise naevus of Ota or oculodermal melanocytosis).

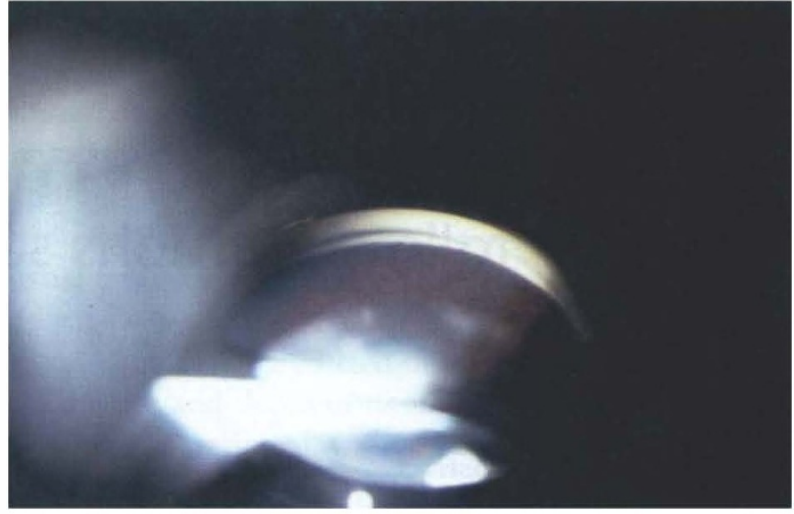

Fig. 3. Right 'rye'. The angle' is ope'n but not wide, with diffuse' heyperpigmentation of the trabecular mesharerk.

nerve cells and abnormal melanocytes, which originate in the embryonal neural crest. However, the pathogenetic mechanism becomes more complicated where there is systemic involvement (type b) as not all sites of origin can be attributed to the neural crest. Indeed, in SturgeWeber syndrome there are lesions that have cells derived from the embryonal mesenchyme. Furthermore, the migration and differentiation of neural crest cells is influenced by the embryogenic environment and extracellular macromolecules such as glycosaminoglycans, fibronectin and collagen, rendering the pathogenetic mechanism even more complex.

In conclusion, the numerous cases of phakomatosis pigmentovascularis and the five cases of Sturge-Weber syndrome and naevus of Ota reported show that there is probably a common pathogenesis. However, further investigation into the molecular biology of neural crest development and angiogenesis of the central nervous system is warranted to determine the aetiology of these coexisting neuro-oculo-cutaneous disorders.

\section{References}

1. Ota M, Kawanura T, Ito N. Phacomatosis pigmentovascularis (Ota). Jpn J Dermatol 1947;52:1-3.

2. Hasegawa Y, Yasuhara M. Phakomatosis pigmentovascularis type IIIb. J Am Acad Dermatol 1993;29:305-7.

3. Arjona J. Sindrome de Sturge Weber con melanosis oculi. Arch Soc Oftal Hisp Am 1948;8:12(1)7-18.

4. Noriega-Sanchez A, Markand ON, Herndon JH.

Oculocutaneous melanosis associated with the Sturge-Weber syndrome. Neurology 1972;22:256-62.

5. Ortonne JP', Floret D, Coiffet J, Cottin X. Syndrome de SturgeWeber associé a une mélanose oculo-cutanée. Ann Dermatol Venereol (Paris) 1978;115:1019-31.

6. Gomez MR, Bebin EM. Sturge-Weber sy'ndrome. In: Gomez MR, editor. Neurocutaneous disease. Stoncham, MA: Butterworth, 1987:chap. 4).

7. Teekhasaenee C, Ritch R, Rutnin U, Leelawongs N. Ocular findings in oculodermal melanocytosis. Arch Ophthalmol 1990);108:1114-20.

8. Kitamura W, Iwai M, Sakamoto K. A case of phacomatosis pigmentovascularis. Rinsho Dermatol 1981;35:399-4(15.

9. Smoller BR, Rosen S. P'ort-wine stains: a disease of altered neural modulation of blood vessels? Arch Dermatol $1986 ; 122: 177-9$. 